Short communications

\section{A new example of a morphine- sensitive neuro-effector junction: adrenergic transmission in the mouse vas deferens}

\section{G. Henderson, J. Hughes AND H. W. KOSTERLITZ}

Department of Pharmacology, University of Aberdeen, Scotland

The isolated mouse vas deferens possesses an adrenergic excitatory motor innervation which can be inhibited by low concentrations of morphine (ID50 $=0.5 \mu \mathrm{M}$ ). This effect of morphine is mediated by specific receptors which are blocked by naloxone. Activation of the morphine receptors inhibits noradrenaline release. It is concluded that adrenergic neurotransmission in the mouse vas deferens differs in some important way from that at the more common, morphine-insensitive, adrenergic junctions.

The effects of morphine on the peripheral nervous system are very selective. For example, morphine inhibits cholinergic transmission in the guinea-pig ileum (Paton, 1957) and rabbit heart (Kosterlitz \& Taylor, 1959) but has no effect on cholinergic transmission in the guinea-pig heart (Kosterlitz \& Taylor, 1959) or rabbit ileum (Greenberg, Kosterlitz \& Waterfield, 1970). This selectivity of action extends to the adrenergic system where the only example of morphine-sensitive neuroeffector transmission found so far is in the cat nictitating membrane (Trendelenburg, 1957 ; Thompson, 1960 ; Cairnie, Kosterlitz \& Taylor, 1961). We have now discovered that morphine inhibits adrenergic neuroeffector transmission in the mouse vas deferens.

Methods.-Male, albino mice, weighing 25-35 g, were killed by cervical dislocation; their vasa deferentia were dissected out and placed in warm Krebs solution of the following composition (mM): $\mathrm{NaCl} 118$, $\mathrm{KCl} 4 \cdot 75, \mathrm{CaCl}_{2} 2 \cdot 54, \mathrm{MgSO}_{4} 1 \cdot 19$, $\mathrm{NaHCO}_{3} 25, \mathrm{KH}_{2} \mathrm{PO}_{4} 0.93$, glucose 11 , tyrosine $0 \cdot 25$, ascorbic acid $0 \cdot 1$, disodium edetate 0.027 . After any semen had been expressed from the lumen, the tissue was set up in an organ bath $(4 \mathrm{ml})$ containing Krebs solution at $37^{\circ} \mathrm{C}$ and gassed with $95 \% \mathrm{O}_{2}$ and $5 \% \mathrm{CO}_{2}$. The responses of the longitudinal muscle were recorded isometrically under a basal tension of 0.5 to 1 gramme. The intramural nerves were excited by rectangular pulses of $1 \mathrm{~ms}$ duration and of supra-maximal strength applied through platinum electrodes placed on either side of the vas. Release of endogenous noradrenaline was measured as described by Hughes (1972), the fluid from the donor bath being assayed for noradrenaline activity on superfused strips of rabbit aorta and iliac artery; to obtain a measurable output of noradrenaline, 3-5 vasa deferentia were set up in the same donor bath. All drug concentrations are given as $\mu \mathrm{M}$.

Results.-The vas deferens of the mouse contracts in response to single electrical pulses; continuous electrical stimulation at $0.1 \mathrm{~Hz}$ resulted in consistent responses over several hours. Contractions to electrical stimulation at $0.1 \mathrm{~Hz}$ were reduced by $80 \%$ by phentolamine hydrochloride ( 360 $\mu \mathrm{M})$ and abolished by bretylium tosylate $(20.6 \mu \mathrm{M})$. The inhibition due to bretylium was not affected by washing out the drug but was reversed by dexamphetamine sulphate $(18.5 \mu \mathrm{M})$. The contractions were not depressed by hyoscine hydrobromide $(0.23 \mu \mathrm{M})$ or hexamethonium bromide (490 $\mu \mathrm{M})$. During electrical stimulation a substance was released which behaved like noradrenaline in that phentolamine reduced the contractions of both assay tissues to noradrenaline and the unknown substance to the same extent, whereas responses to 5-hydroxytryptamine or histamine were not reduced.

Morphine hydrochloride $(0.07-2.3 \mu \mathrm{M})$ caused a dose-dependent inhibition of the contraction to electrical stimulation at $0 \cdot 1$ $\mathrm{Hz}$; this effect reached its maximum within 2 min and was readily reversed by washing the drug out of the bath. From doseresponse curves, the ID50 was calculated to be $0.47 \pm 0.03 \mu \mathrm{M}(n=6)$. Maximally effective concentrations of morphine inhibited the contractions by $75-85 \%$. Naloxone caused a parallel shift of the dose-response curves for morphine to the right. A plot of $\log$ (dose-ratio -1) against log naloxone (M) gave a straight line $(y=0.937 x+7.82)$, from which the dissociation equilibrium constant $\left(K_{e}\right)$ for naloxone was calculated to be $0.0045 \mu \mathrm{M}$. The $\mathrm{pA}_{2}$ of 8.35 was of the same order of magnitude as the value found in the guinea-pig ileum (Kosterlitz \& Watt, 1968). 

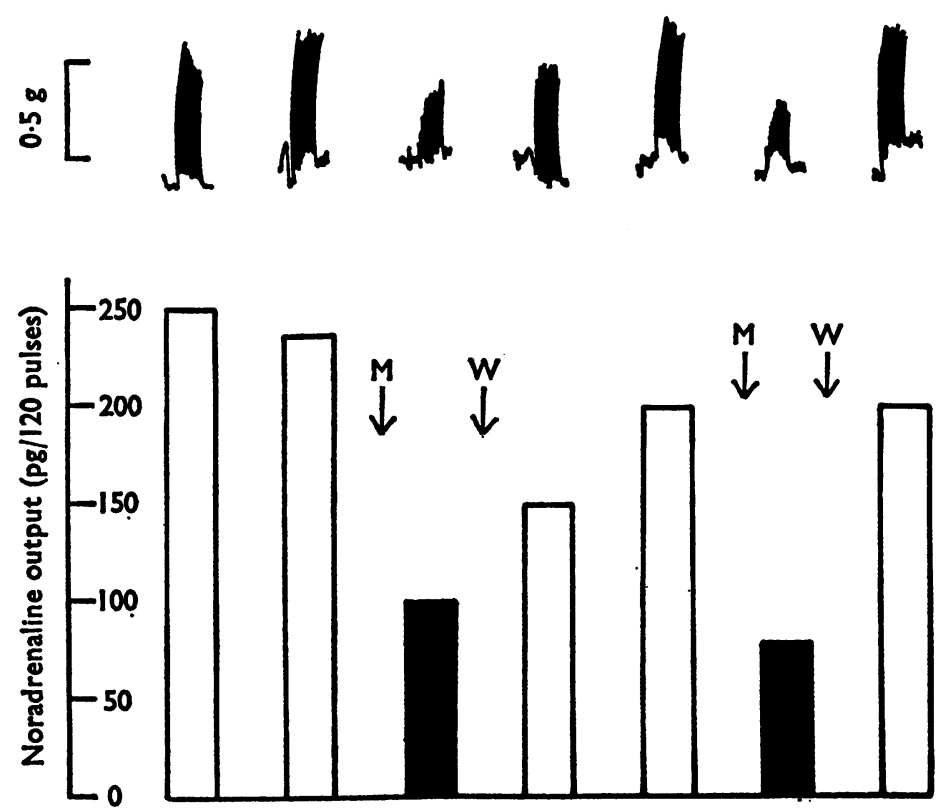

FIG. 1. Mouse vas deferens. Inhibition by morphine of contractions and of noradrenaline output. Four vasa deferentia were stimulated every $15 \mathrm{~min}$ by field stimulation (trains of 120 pulses of $1 \mathrm{~ms}$ duration of supramaximal strength at $1 \mathrm{~Hz}$ ). Morphine (M) was added to the bathing fluid 1 min before stimulation and washed out $(W)$ at the end of the collection period of 3 minutes. Upper panel, contractions recorded isometrically (calibration, $0.5 \mathrm{~g}$ tension). Lower panel, noradrenaline output (pg/120 pulses); clear columns, before and after exposure to morphine; solid columns, during exposure to morphine $(0.7 \mu \mathrm{M})$.

The effect of morphine $(0.7 \mu \mathrm{M})$ on noradrenaline release is shown in Figure 1. The output of noradrenaline and the contraction of the vas elicited by electrical stimulation at $1 \mathrm{~Hz}$ were reduced by 50 to $70 \%$. The effects of morphine on both the mechanical response and the noradrenaline output, were reversed within $15 \mathrm{~min}$ of washing the tissue. These results were repeated in four separate experiments.

Discussion.-Morphine has a potent inhibitory effect on motor transmission in the mouse vas deferens. The results with naloxone leave little doubt that the effect is due to the interaction of morphine with a specific receptor site. Since the dissociation constant obtained for naloxone in this tissue is very similar to that found in the guinea-pig myenteric plexus (Kosterlitz \& Watt, 1968) the receptors are probably of a similar nature. Although our evidence is not yet complete, we would suggest that the motor innervation of the mouse vas deferens is noradrenergic. There is no evidence to suggest that there is a cholinergic component responsible for the contractor response to electrical stimu- lation; a similar conclusion was reached by Farnebo \& Malmfors (1971). It is therefore concluded that morphine directly affects the noradrenaline release mechanism, as it does in the cat nictitating membrane (Henderson, Hughes \& Thompson, 1972). The mouse vas deferens should prove to be a useful tissue for investigating the mode of action of morphine and it may also be suitable as a screening method for narcotic analgesic drugs.

For an understanding of the mode of action of morphine it would appear to be of considerable importance that, whereas transmission in the mouse vas deferens is depressed by morphine, transmission in the vasa deferentia of the rabbit and guineapig are not affected by this drug (Hughes, unpublished observations). Moreover, Henderson et al. (1972) have recently shown that, in the guinea-pig myenteric plexus, adrenergic transmission is morphine-insensitive although it is a wellestablished fact that the cholinergic transmission in this tissue is highly morphinesensitive. Why some synaptic sites are sensitive to morphine and others are not is an open question. As more morphine- 
sensitive sites are found, it is to be hoped that features common to transmission at such synapses, but not at morphine-insensitive sites, will become apparent. From the evidence available so far, two facts may be of importance. First, at junctions where morphine depresses transmission, this effect is observed at low but not at high frequencies of stimulation. Secondly, it has been found that, at such junctions, the output per pulse of acetylcholine or of noradrenaline is particularly high at low frequencies of stimulation; this relationship between frequency of stimulation and output seems to be absent at morphineinsensitive junctions (Greenberg et al., 1972).

Supported in part by grants from the Medical Research Council to J.H. and the Committee on Problems of Drug DependenceU.S. National Academy of Sciences-National Research Grant to H.W.K. G.H. holds a CAPS-SRC Studentship.

\section{REFERENCES}

CAIRnie, A. B., Kosterlitz, H. W. \& TAYLOR, D. W. (1961). Effect of morphine on some sympathetically innervated effectors. $B r . J$. Pharmac. Chemother., 11, 539-551.

FARNEBO, L-O. \& MaLmFors, T. (1971). ${ }^{3} \mathrm{H}-$ Noradrenaline release and mechanical response in the field stimulated mouse vas deferens. Acta physiol. scand., Suppl. 371, 1-18.
GreenberG, R., Kosterlitz, H. W. \& WATERFIELD, A. (1970). The effects of hexamethonium, morphine and adrenaline on the output of acetylcholine from the myenteric plexus-longitudinal muscle preparation of the ileum. Br.J. Pharmac., 40, 553-554P.

Henderson, G., Hughes, J. \& Thompson, J. W. (1972). The variation of noradrenaline output with frequency of nerve stimulation and the effect of morphine in the cat nictitating membrane and the guinea-pig myenteric plexus. Br. J. Pharmac. (Submitted for publication in Proceedings).

HUGHES, J. (1972). Evaluation of mechanisms controlling the release and inactivation of the adrenergic transmitter in the rabbit portal vein and vas deferens. Br.J. Pharmac., 44, 472-491.

Kosterlitz, H. W. \& TAYLOR, D. W. (1959). The effect of morphine on vagal inhibition of the heart. Br.J. Pharmac. Chemother., 14, 209-214.

Kosterlitz, H. W. \& WaTT, A. J. (1968). Kinetic parameters of narcotic agonists and antagonists, with particular reference to $\mathrm{N}$-allylnoroxymorphine (naloxone). $\mathrm{Br} . \mathrm{J}$. Pharmac. Chemother., 32, 266-276.

Paton, W. D. M. (1957). The action of morphine and related substances on contraction and on acetylcholine output of coaxially stimulated guinea-pig ileum. Br. J. Pharmac. Chemother., 12, 119-127.

Thompson, J. W. (1960). The cat's nictitating membrane as an isolated preparation. Ph.D. thesis, University of London.

TRENDELENBURG, U. (1957). The action of morphine on the superior cervical ganglion and on the nictitating membrane. Br. J. Pharmac. Chemother., 12, 79-85.

(Received June 27, 1972) 